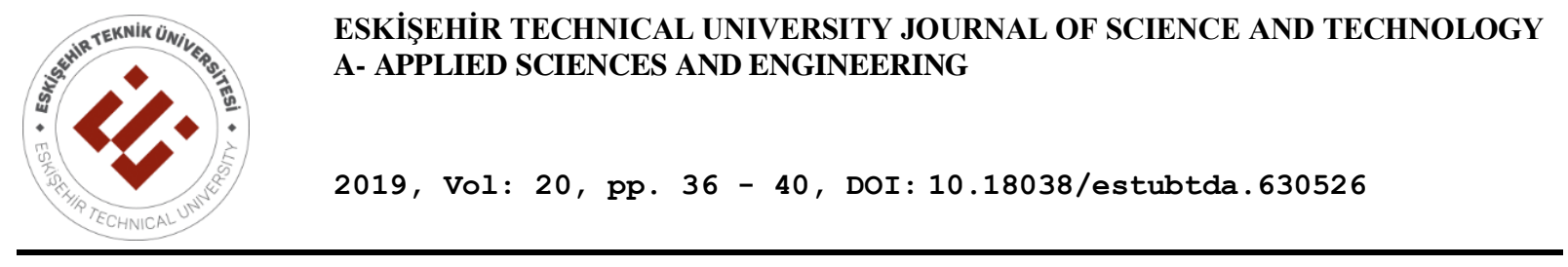

\title{
BRINELL INDENTATION DIAMETER MEASUREMENT WITHOUT USING an OPTICAL MICROSCOPE
}

\author{
Utku KAYA* \\ Program in Railroad Electric and Electronics Tech, Vocational School of Transportation, Eskişehir Technical University \\ Eskisehir, Turkey
}

\begin{abstract}
The Brinell hardness test method has been in common use for over 100 years. The Brinell test method provides hardness measurement near the deformed or cracked zone. In this work, there is an approach to obtaining several railway steel samples' hardness by using a spherical indenter without optical measurement. Spherical indentation diameter is commonly effected by sink-in and pile-up effect that influences optical measurement negatively. Because of that, the purposed approach aims to obtain average hardness values by using indentation and relaxation curves.
\end{abstract}

Keywords: Brinell hardness, Indentation diameter, Spherical indenter, Sink-in, Pile-up

\section{INTRODUCTION}

Brinell hardness is a simple test method for testing hardness of materials by pressing specified test force by using a steel ball or tungsten carbide ball, causing a permanent indentation in the material. Spherical (ball) indentation method is one of the most convenient methods of identification of the elastic-plastic response of the material. This method proposed by Huber and Tsakmakis [1]. The solution of the spherical indentation problems also was proposed in papers by Hill et al. [2], and Biwa and Storakers [3]. Besides that, Attempts to make use of spherical indentation testing to identify the elastic-plastic behaviour of material has been considered in numerous papers. [4-6],

The Brinell hardness value (HBW) is proportional to the test force divided by the surface area. The indentation surface area is determined by measuring the diameter of the indentation after the test force and indenter are removed. HBW can be calculated by using formula 1 below. Typically, the diameter measurement is made by using an optical microscope measuring system.

$$
\mathrm{BHN}=\frac{2 P}{\pi D\left(D-\sqrt{D^{2}-d^{2}}\right)}
$$

BHN $=$ Brinell hardness number $\left(\mathrm{kgf} / \mathrm{mm}^{2}\right)$

$P=$ applied load in kilogram-force (kgf)

$D=$ diameter of indenter $(\mathrm{mm})$

$d=$ diameter of indentation $(\mathrm{mm})$

Spherical indenters give better results for rough surfaces and also results are less affected by defects such as micro-cracks, grain boundaries, and typical micro-casting defects. It means that it is possible to

*Corresponding Author: utkukaya@eskisehir.edu.tr

Received: 02.10.2019 Published: 16.12.2019 
measure hardness near the deformed zone with a spherical indenter. Besides that, spherical indentation methods let us a direct surface measurement without cutting off samples.

Unlike pointed indenters, elastic-plastic, and fully developed plasticity regime of material can be determined by the spherical method because spheres possess the unique ability to transition through perfectly elastic to fully developed plasticity zone. Cylindrical indenter's sharp edges behave like Vickers indenter (as seen in figure 1) which results in exceeding of the elastic regime by small forces

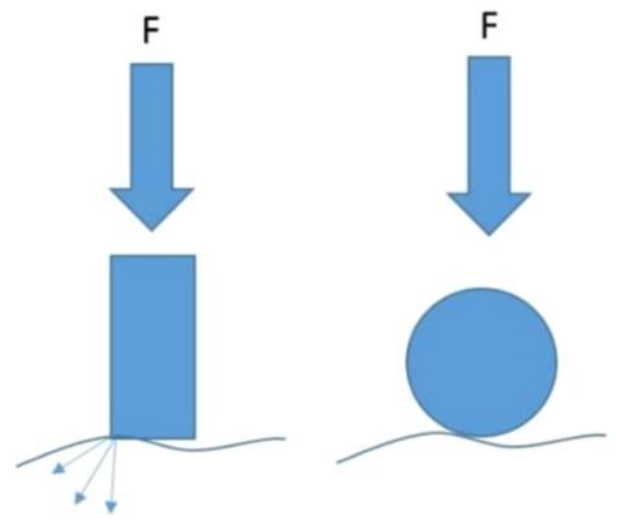

Figure 1. Effects of cylindrical and spherical indenter for an uneven surface.

A large diameter spherical indenter lets us measure hardness and examine mechanical behaviour near the deformed zone. The spherical indenter can determine the mechanical behaviour of a large area without cutting and preparation of the sample. After measuring spherical indentation, there can be some error from optical measurement. The real reason for this error, indentation diameter is effected by sinkin and pile-up effect [7] as seen in figure 2

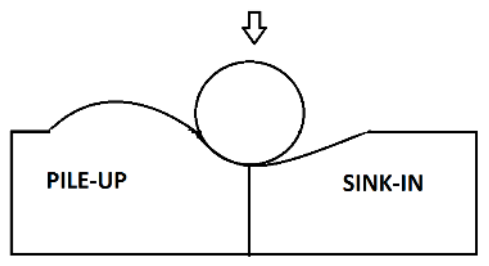

Figure 2. Indentation diameter affected by pile-up or sink-in effect

The main cause of this problem is the edge of the indentation is not a distinct boundary but is instead a curved surface from either material piling up (pile-up) or sinking in (sink-in) caused by plastic flow of the material surrounding the ball indenter. This makes it difficult to measure indentation diameter optically. The purposed methods will be explained in the experimental procedure.

\section{EXPERIMENTAL}

In this paper, we try to obtain comparative Brinell Hardness value (HBW) without using an optical microscope. As mentioned previously indentation diameter is affected by the sink in and pile up effects this results inaccurate HBW readings. 5mm diameter spherical indenter is used for determination of mechanical behaviour as seen in figure 3. Larger diameter indenters affect a larger area and give more 
accurate results. However, choosing a large diameter is limited because of the applied force capacity of the Hardness machine.

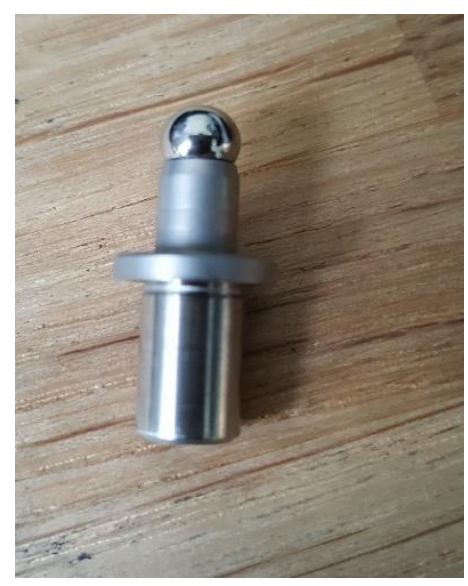

Figure 3. $5 \mathrm{~mm}$ spherical ball indenter

Application of instrumented indentation methods enables the evaluation based on loading force indentation depth, even the study of material response at a particular stage of loading. Typical spherical indentation depth and force graph for two different samples can be seen in figure 4. Curve's deflection between indentation, and relaxation curve was examined for several samples. These deflections seem to be more narrowed (cover less area) for hardened samples. However, it is more expanded behaviour for unhardened samples. The mathematical expression of deflection can be calculated by average indentation depth values between indentation and relaxation curves. Each $\mathrm{P}$ value determines the variation of indentation depth corresponding to the force. We named curve energy deflection change as 'P ${ }_{\text {mean }}$ value'.

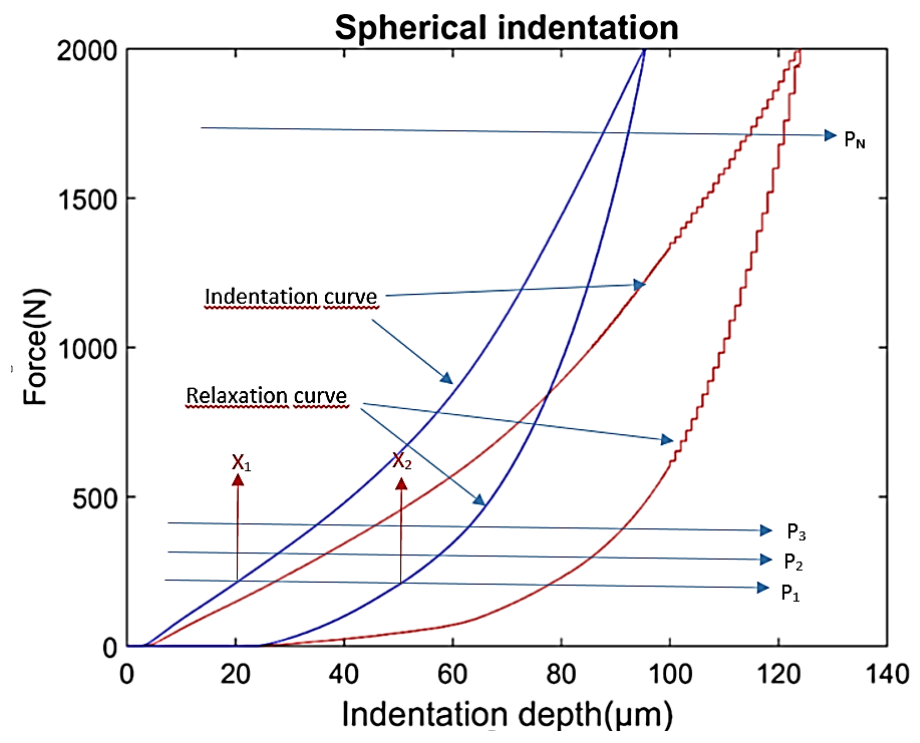

Figure 4. The calculation method of $\mathrm{P}_{\text {mean }}$ value

Each $\mathrm{P}$ value determines the variation of indentation depth corresponding to the force. Each P-value is calculated by 10-newton interval (less interval gives better results) we named curve energy deflection change as ' ${ }_{\text {mean }}$ value"'. P mean value is mean of each $p$ values as seen on formula 
Kaya / Eskişehir Technical Univ. J. of Sci. and Tech. A-Appl. Sci. and Eng. Vol.20-2019

$$
\begin{gathered}
\mathrm{P}_{1}=\mathrm{X}_{2}-\mathrm{X}_{1}\left(\mathrm{P}_{2}, \mathrm{P}_{3}, \ldots ., \mathrm{P}_{\mathrm{N}} \text { can be calculated same }\right) \\
\text { Pmean }=\frac{P_{1}+P_{2}+P_{3}+\cdots+P_{N}}{N}
\end{gathered}
$$

Brinell hardness value (HBW) and $\mathrm{P}_{\text {mean }}$ values are investigated. Several railway materials are tested under $2000 \mathrm{~N}$ for exceeding the elastical limit and $\mathrm{P}_{\text {mean }}$ value calculated for each sample. As we mentioned, $\mathrm{P}_{\text {mean }}$ values are calculated by indentation depths, not by contact diameters (which measured by optical microscope). All results are given in Table 1 .

Table $1 \mathrm{P}_{\text {mean }}$ and contact diameters from several samples

\begin{tabular}{|l|l|l|l|l|}
\hline Samples & Force $(\mathbf{N})$ & $\mathbf{P}_{\text {mean }}$ & Contact diameter $(\boldsymbol{\mu m})$ & $\begin{array}{l}\text { Brinell hardness } \\
\left(\mathbf{N} / \mathbf{m m}^{2}\right)\end{array}$ \\
\hline Ordinary Bainitic & $2000 \mathrm{~N}$ & 27.09 & 124 & 166 \\
\hline Ordinary Pearlitic & $2000 \mathrm{~N}$ & 29.2276 & 129 & 153 \\
\hline Pearlitic 2 & $2000 \mathrm{~N}$ & 25.87 & 124 & 166 \\
\hline Austenite (hardened) & $2000 \mathrm{~N}$ & 16.43 & 96 & 279 \\
\hline Hadfield welded & $2000 \mathrm{~N}$ & 35.13 & 141 & 127 \\
\hline Austenite welded & $2000 \mathrm{~N}$ & 46.97 & 169 & 88 \\
\hline Pearlitic welded & $2000 \mathrm{~N}$ & 26.47 & 126 & 160 \\
\hline
\end{tabular}

$\mathrm{P}_{\text {mean }}$ values are calculated and approximate contact diameters which are affected by the sink-in and pileup effects are measured by optical microscope. Results are compared in Figure 5

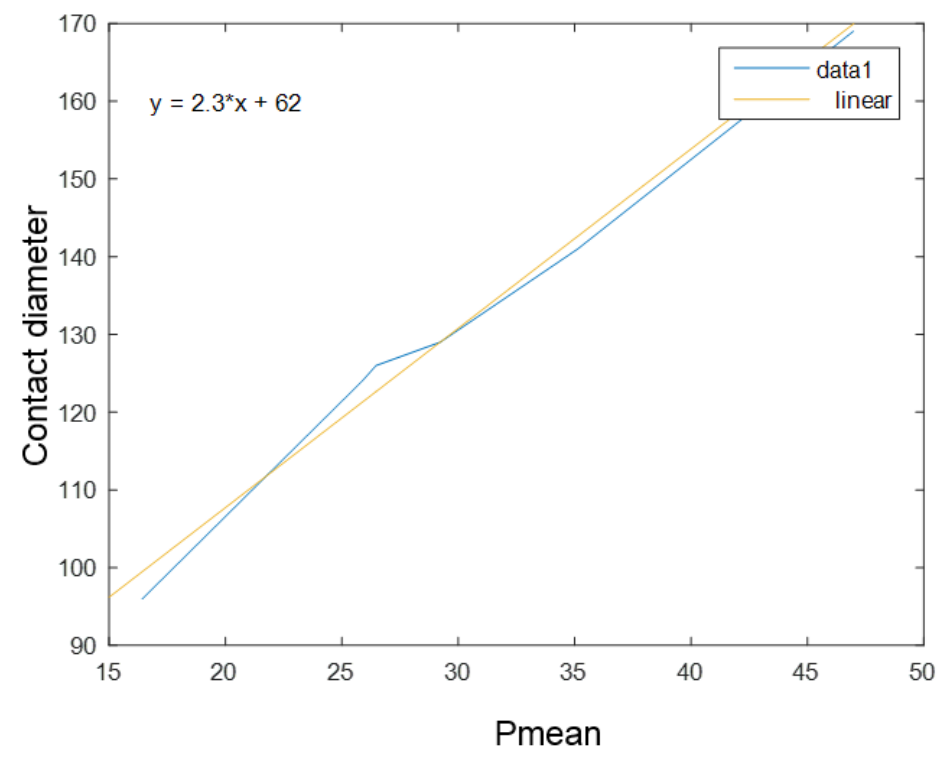

Figure 5. Linear fitting $P_{\text {mean }}$ to Contact diameter 
Each $\mathrm{P}_{\text {mean }}$ and contact diameters compared. It is clear to see that they have a linear relation between them. We get formula 3 by using linear fitting. By using this formula we can obtain approximate Brinell hardness value

$$
\text { Contact diameter }=2.3 x \text { Pmean }+62
$$

\section{CONCLUSION}

Brinell hardness is a simple test method for testing the hardness of the material. Brinell hardness (HBW) is calculated by the diameter of indentation after the test force and indenter are removed. Optically measured diameter is affected by the sink-in and pile-up effect because of that optical test methods have limitations. Introduced method aims to find Brinell hardness value from indentation depth. Because of this, indentation and the relaxation curve energy ratio is calculated by $\mathrm{P}_{\text {mean }}$ method that explained the experimental section. Several samples are tested. Each $\mathrm{P}_{\text {mean }}$ and approximate contact diameter obtained by an optical microscope is compared. Besides this new formula obtained by using linear fitting.

\section{REFERENCES}

[1] Huber N, Tsakmakis Ch. A finite element analysis of the effect of hardening rules on the indentation test. Journal of Engineering Materials and Technology — Transactions of the ASME 1998;120:1438.

[2] Hill R, Storakers B, Zdunek AB. A theoretical study of the Brinell hardness test. Proceedings of the Royal Society of London1989;423:301-30.

[3] Biwa S, Storakers B. An analysis of fully plastic Brinell indentation. Journal of Mechanics and Physics of Solids 1995;43:1303-33.

[4] Field JS, Swain MV. Determining the mechanical properties of small volumes of material from submicrometer spherical indentations. Journal of Materials Research 1995;10(1):101-12.

[5] Adler TA, Dogan ON. Damage by indentation and single impact of hard particles on a high chromium white cast iron. Wear 1997;203-204:257-66.

[6] Taljat B, Zacharia T, Kosel F. New analytical procedure to determine stress-strain curve from spherical indentation data. International Journal of Solids and Structures 1998;35:4411-

[7] ANDERSON DD, WARKENTIN AA, BAUER RR. Simulation of Deep Spherical Indentation Using Eulerian Finite Element Methods. ASME. J. Tribol.2011; 133(2):021401-021401-8. doi:10.1115/1.4003703. 